\title{
PERSEPSI MEREK MEWAH UNTUK MEMBANGUN MINAT BELI
}

\author{
Rifki Candra Nugraha \\ Universitas Pendidikan Indonesia \\ $\underline{\text { rifki.candra.nugraha@student.upi.edu }}$ \\ Ratih Hurriyati \\ Universitas Pendidikan Indonesia \\ $\underline{\text { ratihhurriyati@upi.edu }}$ \\ Dian Herdiana Utama \\ Universitas Pendidikan Indonesia \\ dhutama@upi.edu
}

\begin{abstract}
ABSTRAK
Tujuan - untuk mengetahui pengaruh persepsi merek mewah terhadap minat beli.

Desain/metodologi/pendekatan - penelitian ini dilakukan pada rentang waktu kurang dari satu tahun, maka desain penelitian yang digunakan adalah cross sectional method. Penelitian ini menggunakan pendekatan deskriptif dan verifikatif dengan metode explanatory survei. Sebanyak 370 responden sebagai sampel menggunakan simple random sampling. Angket penelitian digunakan sebagai instrument penelitian untuk mengumpulkan data dari responden serta teknik analisis data yang digunakan adalah regresi linear sederhana.

Temuan - persepsi merek mewah berpengaruh secara signifikan terhadap minat beli.

Orisinalitas - perbedaan ditemukan dalam variabel independen, objek dan metode penelitian, populasi dan sampel penelitian, periode penelitian, alat ukur dan hasil penelitian, serta sumber teori dan jurnal asing dan buku asing.
\end{abstract}

Kata kunci $\quad$ : Persepsi Merek Mewah, Minat Beli

Tipe artikel : Penelitian

\begin{abstract}
Purpose - This study was conducted to know the effect of luxury brand perception on purchase intention. The design / methodology / approach - this study was conducted over a period of less than one year, the research design used was cross sectional method. This research uses descriptive and verifikatif approach with explanatory survey method. A total of 370 respondents as a sample using simple random sampling. Questionnaire research is used as a research instrument to collect data from respondents and data analysis techniques used are simple linear regression.

Findings - the perception of luxury brands have a significant effect on purchase intention.

Originality - differences are found in independent variables, research objects and methods, population and sample studies, research periods, measuring instruments and research results, as well as sources of foreign theories and journals and foreign books.
\end{abstract}

Keywords: Luxury Brand Perception, Purchase Intention Type of article: Research

\section{PENDAHULUAN}

Industri otomotif saat ini adalah salah satu industri yang paling menguntungkan (Klöckner, 2014). Kenaikan pendapatan di sektor pedesaan dan perkotaan serta ketersediaan pembiayaan mudah menjadi pendorong utama industri ini meningkatkan volume penjualannya (Shende, 2014). Akibatnya, perusahaan harus memahami atribut jenis kendaraan yang paling mungkin mempengaruhi penilaian di masyarakat (Schuitema, Anable, Skippon, \& Kinnear, 2013). Pelanggan menginginkan serangkaian perjalannya dilakukan dengan baik oleh kendaraannya (Carley, Krause, Lane, \& Graham, 2013). Tentu saja diyakini secara luas bahwa perubahan perilaku diperlukan untuk mempromosikan masa depan yang lebih berkelanjutan (Bockarjova \& Steg, 2014). Strategi untuk meningkatkan kualitas produk perusahaan 
sebenarnya terlepas dari pernyataan, apa yang dibutuhkan dan dicari oleh konsumen. Kualitas itu sendiri didefinisikan sebagai keseluruhan atribut dan karakteristik produk dan layanan yang menunjukkan kemampuannya untuk memenuhi kepuasan konsumen, baik secara eksplisit maupun implisit (Hurriyati, Surachim, \& Lisnawati, 2016). Persaingan pada bidang industri ini menjadikan peluang dan tantangan bagi perusahaan untuk terus memproduksi produk yang berkualitas, bervariasi dan dapat bersaing serta dapat mempertahankan eksistensi perusahaannya di masa yang akan datang (Utama \& Amelia, 2009).

Salah satu permasalahan utama pada industri otomotif terletak pada minat membeli dari kosumen. Minat membeli menjadi fenomena umum yang terjadi di seluruh dunia (Ackaradejruangsri, 2015). Penerapan metode minat beli untuk mengukur minat terhadap produk, pertama-tama harus menentukan beberapa cara untuk menyampaikan informasi produk ini kepada konsumen potensial (Hosein, 2012). Lingkungan bisnis yang kompetitif dan berubah saat ini, yaitu kekuatan perusahaan dan permintaan pelanggan terus berkembang, menjadikan peningkatan minat beli menjadi sangat penting dan diperlukan untuk kesuksesan serta kelangsungan hidup produsen (Mirabi, Akbariyeh, \& Tahmasebifard, 2015). Usaha meningkatkan minat beli ini sangat penting dilakukan, karena jika minat beli dalam diri konsumen itu tumbuh pada akhirnya akan mendorong konsumen untuk melakukan pembelian (Nurrahman \& Utama, 2016).

Banyak penelitian yang menunjukan rendahnya minat beli menjadi suatu permasalahan di sebuah perusahaan, seperti beberapa penelitian di perusahaan otomotif di Taiwan, Malaysia, Iran, Sri Lanka, dan Amerika Serikat (Wu \& Chen, 2014; Seng \& Husin, 2015; Vahdati \& Nejad, 2016; Karunanayake \& Wanninayake, 2015; Flanagin, Metzger, Pure, Markov, \& Hartsell, 2014). Penelitian-penelitian tersebut menyatakan bahwa permasalahan minat beli menjadi penting untuk perusahaan memahami perilaku minat beli karena dapat membantu dalam meningkatkan penjualan perusahaan. Hal ini menujukan bahwa minat beli masih menjadi permasalahan utama yang dialami banyak perusahaan otomotif di dunia.

Minat beli telah menjadi fokus penting untuk perusahaan otomotif, selanjutnya keberhasilan meningkatkan minat beli tergantung pada bagaimana pelanggan memandang pemberi stimulus (Schmalfuß, Mühl, \& Krems, 2017). Pada dasarnya, niat beli mewakili apa yang konsumen pikir akan mereka beli (Blackwell et.al, 2001; Wee,
2014). Pendapat tersebut diperkuat oleh pendapat Belgiawan et al., (2014) dalam penelitiannya menyebutkan bahwa minat beli menjadi suatu hal yang krusial bagi kesuksesan sebuah perusahaan. Pada umumnya, terlibat dalam pembentukan niat pembelian konsumen adalah sebagai sarana untuk meningkatkan kinerja perusahaan (Dehghani \& Tumer, 2015). Hal-hal yang harus dilaksanakan untuk membangun citra perusahaan adalah dengan menciptakan situasi yang logis, selain itu menciptakan diferensiasi dalam pikiran individu diantara serangkaian pesaing yang memiliki visi dan misi yang hampir sama (Hurriyati \& Sofyani, 2006)

Kesuksesan dan kegagalan perusahaan bergantung pada bagaimana meningkatkan minat membeli konsumen (Huang, Yen, \& Liu, 2014). Kebutuhan konsumen dapat terpenuhi dan bahkan memiliki lebih banyak alternatif dalam penentuan produk untuk memenuhi kebutuhannya (Fitriansyah \& Hurriyati, 2016). Hasil survei dari Nielsen Global Survey of Automotive Demand, menemukan bahwa tingkat kepemilikan mobil relatif rendah adalah di Asia Tenggara. Indonesia termasuk yang terendah, dengan 54 persen rumah tangga memiliki mobil. Sedangkan, Malaysia yang mencatat nilai tertinggi bahkan di tingkat global yaitu 93 persen (http://bisnis.news.viva.co.id diakses tanggal 22 Mei 2017). Data tersebut menunjukan bahwa permasalahan minat membeli kendaraan terutama mobil masih menjadi fokus utama dalam industri otomotif.

Minat beli berdampak langsung pada kelangsungan hidup perusahaan, karena minat membeli merupakan kesediaan konsumen untuk membeli produk tertentu pada waktu tertentu atau dalam situasi tertentu (L. Lu, Chang, \& Chang, 2014). Tujuan utama pemasaran adalah mengajak konsumen untuk berniat membeli produk yang dipasarkan (Hutter, Hautz, Dennhard, \& Fuller, 2013). Dengan demikian, tampaknya logis bahwa niat konsumen untuk membeli pada akhirnya akan menghasilkan keutungan bagi perusahaan (Anderson \& Knight, 2014). Minat pembelian adalah konsekuensi akhir dari sejumlah faktor dalam konteks belanja (Das, 2014). Selain itu, minat beli bisa menjadi indikator penting untuk memprediksi perilaku pembelian (Y. F. Wu, Wu, Lee, \& Tsai, 2014).

Mengingat permasalahan minat beli sangat penting untuk perusahaan otomotif, maka masalah tersebut dapat diatasi dengan pendekatan Perilaku Konsumen yang merupakan salah satu bidang dari Manajemen Pemasaran yang termasuk dalam bagian dari Buying Decision Process (Kotler \& 
Keller, 2016). Schiffman \& Kanuk (2004) berpendapat pengaruh eksternal, kesadaran akan kebutuhan, pengenalan produk dan evaluasi alternatif adalah hal yang dapat menimbulkan minat beli konsumen. Pengaruh eksternal ini terdiri dari usaha pemasaran dan faktor sosial budaya. Menurut Rana, Osman, \& Othman (2015) terdapat faktorfaktor yang mempengaruhi minat beli, yaitu kualitas produk, citra merek, sosio-ekonomi, dan pengaruh sosial.

Berdasarkan beberapa penelitian mengungkapkan bahwa terdapat faktor yang mempengaruhi minat beli diantaranya, pengaruh sosial dan kepercayaan (B. Lu, Fan, \& Zhou, 2016). Wang, Yeh, \& Liao (2013) menambahkan faktor lain, yaitu persepsi nilai ke dalam faktor yang mempengaruhi minat beli. Terdapat juga faktor reputasi dan kualitas website yang dapat mempengaruhi minat beli (Kim \& Lennon, 2012). Jang, Chun, Ko, \& Morris (2014) berpendapat faktor yang dapat mempengaruhi minat beli adalah respon emosional dan persepsi akan nilai. Pendapat tersebut diperkuat oleh Eom \& Seock (2015) yang menyebutkan bahwa persepsi merek mewah mempengaruhi minat beli.

Karakteristik merek mewah sendiri menurut JD Power and Associate, yang merupakan salah satu penyedia informasi pemasaran global, dalam laman resminya menyatakan antara lain adalah harga yang meliputi kualitas, reliabilitas, dan penilaian ketertarikan, lalu ada efisiensi bahan bakar, penilaian keamanan, dan volume muatan (http://jdpower.com diakses 7 September 2017). Sebuah kendaraan harus dapat memenuhi karakteristik tersebut untuk memposisikan diri sebagai salah satu kendaraan mewah. Penilaian yang dilakukan untuk mengukur merek mewah dilakukan oleh para ahli di bidang tersebut secara objektif berdasarkan indikator-indikator yang ada.

Berdasarkan rumusan masalah di atas, maka tujuan penelitian ini adalah untuk memperoleh hasil temuan mengenai: (1) memperoleh temuan gambaran persepsi merek mewah, (2) memperoleh temuan gambaran minat beli, (3) memperoleh temuan pengaruh persepsi merek mewah terhadap minat beli.

\section{KAJIAN PUSTAKA}

Pemasaran dapat didefinisikan sebagai seni dan sains untuk memilih pasar sasaran dan mendapatkan, mempertahankan, dan menumbuhkan pelanggan melalui penciptaan, penyampaian, dan pengomunikasian nilai pelanggan yang superior. (Kotler \& Keller, 2016:27). Menurut Kotler \& Keller (2016:179) pemasar harus benar-benar memahami teori dan kenyataan perilaku konsumen. Pengertian dari perilaku konsumen sendiri adalah studi tentang bagaimana individu, kelompok, dan organisasi memilih, membeli, menggunakan, dan membuang barang, jasa, gagasan, atau pengalaman untuk memenuhi kebutuhan dan keinginan mereka. Perilaku pembelian konsumen dipengaruhi oleh faktor budaya, sosial, dan pribadi. Dari jumlah tersebut, faktor budaya memberikan pengaruh yang paling luas dan terdalam Kotler \& Keller (2016:179).

Perilaku konsumen mencerminkan keseluruhan keputusan konsumen sehubungan dengan perolehan, konsumsi, dan disposisi barang, layanan, aktivitas, pengalaman, orang, dan gagasan oleh unit pengambilan keputusan (manusia) dari waktu ke waktu (Hoyer, Macinnis, \& Pieters, 2016:3). Perilaku konsumen mencakup semua aktivitas konsumen yang terkait dengan pembelian, penggunaan, dan pembuangan barang dan jasa, termasuk tanggapan emosional, mental, dan perilaku konsumen yang mendahului, menentukan, atau mengikuti aktivitas ini (Hoyer et al., 2016:8).

Dalam perilaku konsumen terdapat Internal Influeces yang meliputi perception, learning, memory, motives, personality, emotions, dan attitudes (Hoyer et al., 2016:274). Persepsi (perception) dalam hal ini memiliki peranan penting dalam pembentukan keputusan konsumen dalam menentukan suatu tindakan. Persepsi adalah proses yang dimulai dengan paparan konsumen dan perhatian terhadap rangsangan pemasaran dan diakhiri dengan interpretasi konsumen.

Menurut Brun \& Castelli (2013) secara historis barang-barang mewah selalu dikaitkan dengan kekayaan, eksklusivitas dan kekuatan, serta kepuasan kebutuhan non-dasar. Solomon, Bamossy, Askeegard, \& Hogg, (2013:219) menyatakan merek mewah menawarkan janji kesenangan kepada pengguna yang membuat konsumen bisa termotivasi untuk membeli produk tersebut. Menurut Kotler \& Keller (2016:416) menyatakan bahwa kemewahan merek ditampilkan harga premium dan kerap memiliki komponen gaya hidup yang kuat. Menurut Zarantonello (2016:119) berpendapat bahwa dimensi persepsi merek mewah yaitu, dirasa menarik, dirasa unik, dirasa berkualitas, dirasa hedonis, dirasa memperbaiki diri. Berdasarkan model Steps Between Evaluation of Alternatives and a Purchase Decision, salah satu kajiannya adalah minat beli. Perilaku yang mencerminkan niat ini karena dipengaruhi oleh situasi di mana perilaku tersebut akan terjadi (Hawkins, D. I., Mothersbaough, 2011;390). Pada tahap evaluasi, konsumen 
membentuk preferensi di antara yang ada dalam pilihan dan juga merupakan niat untuk membeli produk yang paling disukai (Kotler \& Keller, 2016;198). Perilaku melibatkan minat seseorang tersebut untuk melakukan sesuatu sehubungan dengan sikap terhadap objek (Solomon, Bamossy, Askeegard, \& Hogg, 2013;294).

Minat beli adalah keinginan untuk memiliki produk yang muncul apabila seseorang konsumen sudah terpengaruh terhadap mutu dan kualitas dari suatu produk, serta informasi seputar produk (Durianto, 2011;58). Sedangkan menurut Shah et al. (2012) minat beli adalah semacam pengambilan keputusan yang mempelajari alasan membeli merek tertentu oleh konsumen. Niat beli didefinisikan sebagai ukuran kekuatan niat seseorang untuk melakukan perilaku tertentu atau membuat keputusan untuk membeli produk, barang atau jasa (Amoroso \& Morco, 2016). Keller, (2013:345) menyatakan dimensi minat beli antara lain adalah, tindakan (membeli untuk penggunaan sendiri atau memberi hadiah), target (jenis produk dan merek tertentu), konteks (dalam jenis toko apa berdasarkan harga dan kondisi lainnya), waktu (dalam seminggu, bulan, atau tahun).

Menurut Tan (2016) terdapat luxury brand perception yang dapat mempengaruhi minat beli. Dengan mengetahui faktor dominan yang membangun perspektif pasar terhadap produk mewah, perusahaan dapat menciptakan usaha yang efektif dan efisien untuk mendapatkan niat beli dan memenuhi kebutuhan dan keinginan konsumen berdasarkan karakteristik tersebut.

Gambar 1. Paradigma Penelitian

\begin{tabular}{|l|l|}
\hline $\begin{array}{l}\text { Persepsi Merek } \\
\text { Mewah } \\
\text { 1. Dirasa Menarik } \\
\text { 2. Dirasa Unik } \\
\text { 3. Dirasa } \\
\text { Berkualitas } \\
\text { 4. Dirasa Hedonis } \\
\text { 5. Dirasa } \\
\text { Memperbaiki Diri }\end{array}$ \\
\hline
\end{tabular}

\section{METODE PENELITIAN}

Penelitian ini menganalisis pengaruh persepsi merek mewah terhadap minat beli.
Variabel bebas dalam penelitian ini yaitu persepsi merek mewah dengan dimensinya yaitu dirasa menarik, dirasa unik, dirasa berkualitas, dirasa hedonis, dan dirasa memperbaiki diri. Serta variabel terikat yaitu minat beli dimensinya mencakup tindakan, target, konteks, dan waktu.

Berdasarkan tingkat penjelasan dan bidang penelitian, maka jenis penelitian ini adalah penelitian deskriptif dan verifikatif. Umar, (2014:21) mengemukakan bahwa, penelitian deskriptif adalah penelitian yang dilakukan untuk mengetahui nilai variabel mandiri, baik satu variabel atau lebih tanpa membuat perbandingan atau menghubungkan dengan variabel lain. Penelitian verifikatif atau penelitian kausalitas diartikan sebagai penelitian yang dilakukan terhadap populasi atau sampel tertentu dengan tujuan untuk menguji hipotesis yang telah ditetapkan (Sugiyono, 2017)

Berdasarkan jenis penelitian deskriptif dan verifikatif yang dilaksanakan melalui pengumpulan data di lapangan, maka metode yang digunakan dalam penelitian ini adalah explanatory survey.

\section{HASIL DAN PEMBAHASAN}

Menurut (Zarantonello, 2016;119) berpendapat bahwa dimensi persepsi merek mewah yaitu dirasa menarik, dirasa unik, dirasa berkualitas, dirasa hedonis, dan dirasa memperbaiki diri. Berdasarkan hasil penelitian dari angket yang disebar kepada 370 responden diketahui bahwa persepsi merek mewah pada produk mobil Mazda Biante mencapai skor 40757 dari skor kriterium atau jumlah maksimal perolehan nilai responden terletak pada daerah efektif yaitu pada interval 37158,5 - 43184,2, sehingga dapat dikatakan bahwa dalam penelitian ini persepsi merek mewah yang dimiliki oleh produk mobil Mazda Biante telah diaplikasikan dengan efektif, namun persepsi merek mewah pada produk ini perlu ditingkatkan lagi karena semua dimensi berada dibawah skor ideal.

Minat beli timbul dari pengaruh orang lain yang dipercaya oleh konsumen (Kotler \& Keller, 2016;199). Menurut Shah et al. (2012) minat beli adalah semacam pengambilan keputusan yang mempelajari alasan membeli merek tertentu oleh konsumen. Niat beli 
didefinisikan sebagai ukuran kekuatan niat seseorang untuk melakukan perilaku tertentu atau membuat keputusan untuk membeli produk, barang atau jasa (Amoroso \& Morco, 2016).

Berdasarkan hasil penelitian dari angket yang disebar kepada 370 responden diketahui bahwa minat beli pada produk mobil Mazda Biante mencapai skor 22952 dari skor kriterium atau jumlah maksimal perolehan nilai responden terletak pada daerah efektif yaitu pada interval 21512,5 - 25001, sehingga dapat dikatakan bahwa dalam penelitian ini minat beli yang dimiliki oleh produk mobil Mazda Biante telah diaplikasikan dengan efektif, namun minat beli pada produk ini perlu ditingkatkan lagi karena semua dimensi berada dibawah skor ideal.

Berdasarkan hasil penelitian dari angket yang disebar kepada 370 responden diketahui bahwa minat beli pada produk mobil Mazda Biante mencapai skor 22952 dari skor kriterium atau jumlah maksimal perolehan nilai responden terletak pada daerah efektif yaitu pada interval 21512,5 - 25001, sehingga dapat dikatakan bahwa dalam penelitian ini minat beli yang dimiliki oleh produk mobil Mazda Biante telah diaplikasikan dengan efektif, namun minat beli pada produk ini perlu ditingkatkan lagi karena semua dimensi berada dibawah skor ideal.

\section{KESIMPULAN DAN REKOMENDASI}

Hasil penelitian menunjukan bahwa gambaran persepsi merek mewah pada produk mobil Mazda Biante secara menyeluruh memiliki pengaruh yang signifikan dan dikategorikan baik pengaruhnya terhadap minat beli, tetapi ada beberapa yang perlu dilakukan perbaikan yaitu dimensi dirasa unik memiliki nilai paling rendah pengaruhnya pada minat beli, sehingga perusahaan perlu meningkatkan keunikan dan ciri khas dari produk mobilnya agar lebih baik lagi.

Gambaran minat beli pada produk mobil Mazda Biante secara menyeluruh dikategorikan baik. Tetapi ada beberapa yang perlu dilakukan perbaikan yaitu dimensi konteks unik memiliki nilai paling rendah, sehingga perusahaan perlu meningkatkan konteks dalam kegiatan pemasarannya agar membantu konsumen lebih mengenal produk mobil Mazda Biante.

Hasil penelitian ini menyatakan bahwa persepsi merek mewah berpengaruh terhadap minat beli. Maka penulis merekomendasikan agar sekolah dapat meningkatkan nilai minat beli melalui persepsi merek mewah.

\section{DAFTAR PUSTAKA}

Ackaradejruangsri, P. (2015). Thai Consumer Behavior on Brand-New Car Purchasing: Influential Factors and Decision Making POS Approach Ackaradejruangsri. World Review of Business Research, 5(3), 80-90.

Amoroso, D. L., \& Morco, R. (2016). E-Commerce Online Purchase Intention: Importance of Corporate Social Responsibility Issues. Encyclopedia of E-Commerce Development, Implementation, and Management, 17. https://doi.org/10.4018/978-1-4666-97874.ch114

Anderson, K. C., \& Knight, D. K. (2014). Influence of hedonic and utilitarian motivations on retailer loyalty and purchase intention: A facebook perspective purchase intention: a facebook perspective. Journal of Retailing and Consumer Services, 21(5), 773-779. https://doi.org/10.1016/j.jretconser.2014.05.0 07

Belgiawan, P. F., Schmo, J., Abou-zeid, M., Walker, J., Lee, T., Ettema, D. F., \& Fujii, S. (2014). Car ownership motivations among undergraduate students in China, Indonesia, Japan, Lebanon, Netherlands, Taiwan, and USA.

Transportation. https://doi.org/10.1007/s11116-014-9548-z

Bockarjova, M., \& Steg, L. (2014). Can Protection Motivation Theory predict proenvironmental behavior? Explaining the adoption of electric vehicles in the Netherlands. Global Environmental Change, 28 276-288. https://doi.org/10.1016/j.gloenvcha.2014.06.0 10

Brun, A., \& Castelli, C. (2013). The nature of luxury: a consumer perspective. Retail \& Distribution Management, 41, 823-834.

Carley, S., Krause, R. M., Lane, B. W., \& Graham, J. D. (2013). Intent to purchase a plug-in electric vehicle: A survey of early impressions in large U.S. Transportation Research Part D: Transport and Environment, 18, 39-45.

Das, G. (2014). Journal of Retailing and Consumer 
Services Linkages of retailer awareness, retailer association, retailer perceived quality and retailer loyalty with purchase intention: A study of Indian food retail brands. Journal of Retailing and Consumer Services, 21(3), 284-292.

https://doi.org/10.1016/j.jretconser.2014.02.0 05

Dehghani, M., \& Tumer, M. (2015). A research on effectiveness of Facebook advertising on enhancing purchase intention of consumers. Computers in Human Behavior, 49, 597-600. https://doi.org/10.1016/j.chb.2015.03.051

Durianto, D. (2011). Strategi Menaklukkan Pasar Melalui Riset Ekuitas dan Perilaku Merek. Jakarta: PT. Gramedia Pustaka Utama.

Eom, H. J., \& Seock, Y.-K. (2015). Factors Influencing Purchase Intention toward Luxury Fashion Brands. International Textile and Apparel Association (ITAA) Annual Conference Proceedings, 72, 22-24.

Fitriansyah, K. A., \& Hurriyati, R. (2016). Analisis Kinerja Interpersonal Relationship terhadap Customer Loyalty. Journal of Business Management Education, 1(1), 1-5.

Flanagin, A. J., Metzger, M. J., Pure, R., Markov, A., \& Hartsell, E. (2014). Mitigating risk in ecommerce transactions: perceptions of information credibility and the role of usergenerated ratings in product quality and purchase intention. Electron Commerce Research, 14, 1-23.

Hawkins, D. I., Mothersbaough, D. L. (2011). Consumer Behavior. New York: Mc Graw Hill.

Hosein, N. Z. (2012). Measuring the Purchase Intention of Visitors to the Auto Show. Journal of Management and Marketing Research, 1-17.

Hoyer, W. D., MacInnis, Deborah J. \& , Pieters ,Rik. (2016). Consumer Behavior. US: Cengage Learning.

Huang, C.-C., Yen, S.-W., \& Liu, C.-Y. (2014). The Relationship Among Corporate Social Responsibility, Service Quality, Corporate Image And Purchase Intention. The International Journal of Organizational Innovation, 6(3), 68-84.

Hurriyati, R., \& Sofyani, S. (2006). Pengaruh Corporate Social Responsibility terhadap Corporate Image PT Bank Negara Indonesia, TBK Ratih Hurriyati Santi Sofyani. Strategic, 9(18), 63-75.

Hurriyati, R., Surachim, A., \& Lisnawati. (2016).
Improving the Competitiveness of UPI as a Research-Based Teaching University. Journal of Physics: Conference Series, 180(1). https://doi.org/10.1088/17426596/755/1/011001

Hutter, K., Hautz, J., Dennhard, S., \& Fuller, J. (2013). The impact of user interactions in social media on brand awareness and purchase intention: the case of MINI on Facebook. Journal of Product \& Brand Management, 22(516), 342-351. https://doi.org/10.1108/JPBM-05-2013-0299

Jang, W., Chun, J., Ko, Y. J., \& Morris, J. D. (2014). The Limited Edition Products: The Role Of Emotional Responses On Perceived Value And Purchase Intention. American Academy of Advertising.

Karunanayake, R. K. T., \& Wanninayake, W. M. C. B. (2015). Impact of Key Purchasing Determinants on Purchase Intention of Hybrid Vehicle Brands in Sri Lanka, an Empirical Study. Journal of Marketing Management, $3(1)$, $40-52$. https://doi.org/10.15640/jmm.v3n1a4

Keller, K. L. (2013). Strategic Brand Management. Essex: Pearson Education Ltd.

Kim, J., \& Lennon, S. J. (2012). Effects of reputation and website quality on online consumers' emotion, perceived risk and purchase intention model. Journal of Research in Interactive Marketing, 7(1), 3356. https://doi.org/10.1108/17505931311316734

Klöckner, C. A. (2014). The Dynamics of Purchasing an Electric Vehicle - A Prospective Longitudinal Study of the Decision-Making Process. Transportation Research, 24, 103-116. https://doi.org/10.1016/j.trf.2014.04.015

Kotler, P., \& Keller, K. L. (2016). Marketing Management. Essex: Pearson Education Ltd.

Lu, B., Fan, W., \& Zhou, M. (2016). Social presence, trust, and social commerce purchase intention: An empirical research. Computers in Human Behavior, 56, 225-237. https://doi.org/10.1016/j.chb.2015.11.057

Lu, L., Chang, W., \& Chang, H. (2014). Consumer attitudes toward blogger ' $\mathrm{s}$ sponsored recommendations and purchase intention: The effect of sponsorship type , product type , and brand awareness. Computers in Human Behavior, 34, 258-266. https://doi.org/10.1016/j.chb.2014.02.007

Mirabi, V., Akbariyeh, H., \& Tahmasebifard, H. (2015). A Study of Factors Affecting on 
Customers Purchase Intention Case Study: the Agencies of Bono Brand Tile in Tehran. Journal of Multidisciplinary Engineering Science and Technology (JMEST), 2(1), 267273.

Nurrahman, I., \& Utama, D. H. (2016). Pengaruh Variasi Produk terhadap Keputusan Pembelian (Survei pada pembeli smartphone Nokia series X di BEC Bandung). Journal of Business Management Education, 1(1), 5665.

Rana, S. M. S., Osman, A., \& Othman, Y. H. (2015). Factors Affecting Purchase Intention of Customers to Shop at Hypermarkets. Mediterranean Journal of Social Sciences, $6(3)$, 429-434. https://doi.org/10.5901/mjss.2015.v6n3p429

Schiffman, L. G. L., \& Kanuk, L. (2004). Perilaku Konsumen. Jakarta: PT. Indelks Gramedia.

Schmalfuß, F., Mühl, K., \& Krems, J. F. (2017). Direct experience with battery electric vehicles (BEVs) matters when evaluating vehicle attributes, attitude and purchase intention. Transportation Research Part F: Traffic Psychology and Behaviour, 46, 47-69.

Schuitema, G., Anable, J., Skippon, S., \& Kinnear, N. (2013). The role of instrumental, hedonic and symbolic attributes in the intention to adopt electric vehicles. Transportation Research Part A: Policy and Practice, 48, 39-49.

Seng, L. C., \& Husin, Z. (2015). Product and Price Influence on Cars Purchase Intention in Malaysia. International Research Journal of Interdisciplinary \& Multidisciplinary Studies (IRJIMS), 1(7), 108-119.

Shah, H., Aziz, A., Jaffari, A. R., Waris, S., W., E., Fatima, M., \& Sherazi, K. (2012). The Impact of Brands on Consumer Purchase Intentions. Asian Journal of Business Management, 4(2), 105-110.

Shende, V. (2014). Analysis of Research in Consumer Behavior of Automobile Passanger Car Customer. International Journal of Scientific and Research Publications, 4(2), 18.

Solomon, M., Bamossy, G., Askeegard, S., \& Hogg, M. K. (2013). Consumer Behavior: an European Perspective. Essex: Pearson Education Ltd.

Sugiyono. (2017). Statistika Untuk Penelitian. Bandung: Alfabeta.

Tan, C. S. L. (2016). Does Luxury Really Care? How Cause Related Marketing Shapes Brand Perception And Purchase Intention In The
Japanese Luxury Market. Global Marketing Conference at Hong Kong.

Umar, H. (2014). Metode Riset Bisnis. Jakarta: PT.Gramedia Pustaka Utama.

Utama, D. H., \& Amelia, F. (2009). Pengaruh Atribut Produk terhadap Kepuasan Pelanggan Produk Teh Celup Sosro dan 2 Tang. Jurnal Pendidikan Manajemen Bisnis, 8(16), 30-40.

Vahdati, H., \& Nejad, S. H. M. (2016). Brand Personality Toward Customer Purchase Intention: The Intermediate Role Of Electronic Word-Of-Mouth And Brand Equity. Asian Academy of Management Journal, 21(2), 1-26.

Wang, Y., Yeh, C., \& Liao, Y. (2013). What drives purchase intention in the context of online content services? The moderating role of ethical self-efficacy for online piracy. International Journal of Information Management, 33(1), 199-208. https://doi.org/10.1016/j.ijinfomgt.2012.09.00 4

Wee, C. S. (2014). Consumers Perception, Purchase Intention and Actual Purchase Behavior of Organic Food Products. Society of Interdisciplinary Business Research, 3(2), 378-397.

Wu, S., \& Chen, Y. (2014). The Impact of Green Marketing and Perceived Innovation on Purchase Intention for Green Products. International Journal of Marketing Studies, 6(5), 81-100. https://doi.org/10.5539/ijms.v6n5p81

Wu, Y. F., Wu, C. Sen, Lee, C. J., \& Tsai, L. F. (2014). The Relationship Between Package Redesign And Purchase Intention. The International Journal of Organizational Innovation, 6(3), 50-62.

Zarantonello, L. (2016). The Handbook of Brand Management Scales. USA: Routledge. 